\title{
Molecular docking study of copaíba oil interacting with the spike protein of Sars-CoV-2
}

\section{Willian Oliveira Santos}

UFAL: Universidade Federal de Alagoas

José Robson da Costa Venâncio

UFAL: Universidade Federal de Alagoas

Fernanda Carla Lima Ferreira

UNIFESSPA: Universidade Federal do Sul e Sudeste do Para

Glaura Caroena Azevedo de Oliveira

UNIFESSPA: Universidade Federal do Sul e Sudeste do Para

Aldimar Machado Rodrigues

UNIFESSPA: Universidade Federal do Sul e Sudeste do Para

Nilton Ferreira Frazão

Universidade Federal de Campina Grande

Erico Raimundo Pereira Novais ( $\nabla$ ericonovais@gmail.com )

Universidade Federal do Sul e Sudeste do Para https://orcid.org/0000-0002-3669-9082

Divanizia do Nascimento Souza

UFS: Universidade Federal de Sergipe

Andrea de Lima Ferreira Novais

UNIFESSPA: Universidade Federal do Sul e Sudeste do Para

\section{Research Article}

Keywords: Docking molecular, Copaíba oil, Covid-19, Inhibitors

Posted Date: August 30th, 2021

DOI: https://doi.org/10.21203/rs.3.rs-841081/v1

License: (c) (1) This work is licensed under a Creative Commons Attribution 4.0 International License.

Read Full License 


\title{
Molecular docking study of copaíba oil interacting with the spike protein of Sars-CoV-2
}

\author{
Willian Oliveira Santos \\ Instituto de Física, Universidade Federal de Alagoas, Maceió, Alagoas, Brazil. \\ José Robson da Costa Venâncio \\ Instituto de Física, Universidade Federal de Alagoas, Maceió, Alagoas, Brazil.
}

Fernanda Carla Lima Ferreira

Faculdade de Física, Universidade Federal do Sul e Sudeste do Pará, Marabá, Pará, Brazil.

Glaura Caroena Azevedo de Oliveira

Faculdade de Física, Universidade Federal do Sul e Sudeste do Pará, Marabá, Pará, Brazil.

Aldimar Machado Rodrigues

Instituto Federal do Pará, Altamira, Pará, Brazil.

Nilton Ferreira Fraz ao

Unidade Acadêmica de Física e Matemática, Universidade Federal de Campina Grande,

Laboratório de Simulação Computacional e Modelagem de Nanomateriais, Cuité, Paraíba, Brazil.

Erico Raimundo Pereira de Novais ${ }^{1}$

Faculdade de Física, Universidade Federal do Sul e Sudeste do Pará, Marabá, Pará, Brazil.

Divanizia do Nascimento Souza

Departamento de Física, Universidade Federal de Sergipe, Aracaju, Sergipe, Brazil.

Andrea de Lima Ferreira Novais

Faculdade de Engeharia Mecânica, Universidade Federal do Sul e Sudeste do Pará, Marabá, Pará, Brazil.

\begin{abstract}
COVID-19 triggered by Sars-CoV-2 has caused hundreds of thousands of deaths worldwide. Organic and inorganic compounds have been tested as potential in-
\end{abstract}

\footnotetext{
${ }^{1}$ Corresponding author: Erico Novais - ericonovais@gmail.com
} 
hibitors of this lethal virus. For these tests, several techniques are use to design molecules of biological interest for drug composition, in which molecular coupling plays an important role. In the present work, the compounds acids kaurenoic, copalic, and beta-caryophyllene that form the copaiba oil were studied as anti-inflammatories and opens the possibility to inhibit Sars-CoV-2. Molecular docking showed alkyl, pi-alkyl, conventional H-bond, unfavorable bump, and Van der Waals interactions. The calculated electrostatic potential maps showed the nucleophilic and electrophilic regions. The negative binding energies obtained for the three acids suggest the stability of the complexes. The minimum energy states for $\beta$-caryophyllene are lower than the other compounds analyzed, and it can be predicted that this is the most stable.

Key words: Docking molecular; Copaíba oil; Covid-19; Inhibitors.

\section{Introduction}

The first Coronavirus was discovered in the 1930s [1, but severe acute respiratory syndrome (Sars) gained notoriety in the world between the years 20022003 [2. At the end of 2019, Sars-CoV-2 triggered a pandemic that has already caused nearly 3.5 million deaths worldwide $[3$.

From serological analyzes and genetic studies, it it is possible to classify the coronaviruses into four different genera: $\alpha, \beta, \gamma$ and $\beta-\mathrm{CoV}$ [4]. $\beta$-CoV type is the cause of the COVID-19 found in Wuhan, China [5]. The Coronaviruses are

enveloped, spherical, or pleomorphic viruses and can vary their shape according to the period of the reproductive life cycle or environmental conditions, with typical sizes ranging from 80 to $120 \mathrm{~nm}$ [4. The coronavirus spike protein is a multifunctional molecular machine that initially binds to a receptor on the surface of the host cell through its S1 subunit and then fuses viral and host membranes through its $\mathrm{S} 2$ subunit, leading to viral binding [6].

We are investigating the inhibitory potential of Copaiba oil against the COVID-19 virus, and we associated the oil compounds with the binding of the Sars-COV-2 spike protein receptor as a target using molecular docking for these calculations. Molecular docking has been used by pharmaceutical companies to study the Structure-Activity Relationship of drugs for more than three decades. New drugs have been discovered and developed during these years [7.

This method gives the possibility to predict both the binding affinity between ligand and protein and the structure of the protein-ligand complex using the computational method, which is relevant information for optimization [8, 9 . Molecular docking techniques aim to predict the best matching binding mode of a ligand to a macromolecular partner. It consists of the generation of several possible conformations/orientations [10. Docking is a technique of designing drug molecules by simulating the geometry of these molecules and their intermolecular forces 3 . In this way, molecular docking optimizes the ligand bound to the active site of the receptor protein and investigates protein-ligand interactions. Molecular coupling algorithms provide results for quantitative energy 
binding markers, including a variety of coupled compounds supported by the binding affinity of ligand-receptor complexes with pharmacokinetic properties. From this calculation, we can predict the different interactions between the oil compounds and the spike protein. Ligand-protein interactions are involved in many biological processes with consequent pharmaceutical industry implications [10].

Several studies have been done on Copaiba oils, mainly due to the interest from the pharmacological and food industries around the globe [11. The Brazilian Amazon concentrates a large number of natural resources species with various therapeutic applications in alternative medicine. Copaiba oil is an oleoresin extracted from the trunk of trees of the Copaifera genus (Fabaceae). Frequently, copaiba grows in tropical regions of South America. The oil-resin is a natural product of the Amazon's biodiversity. Copaiba oil is commonly used in folk medicine to treat multiple diseases, such as ulcers, wounds, syphilis, bronchitis, and inflammation [12].

Scientific researches with copaiba demonstrated that the copaifera reticulate oleoresin exhibits some biological actions such as anti-inflammatory, analgesic, antioxidant, anxiolytic, and antimicrobial activities, and neutrophilic activation [13-15].

Besides these properties, some studies suggest that these species are free from toxicity and teratogenic activity during pregnancy [16]. Also, the copaiba oil can be used as an anti-tumor, anti-inflammatory, antimicrobial against a wide range of microorganisms, and healing on different tissues of the human body.

In several animal models, studies demonstrated that copaiba oil has healing and anti-inflammatory effects. Besides, anti-inflammatory and anti-tumor properties of copaiba oils have been described in several works [17 20]. Those results are significant because they can the designed as applications to improve the quality of life in a society.

\section{Computational details}

Initially, the constituent compounds of the copaiba oil were accessed in the ChemSpider database. All compounds were subjected to a classical simulation to find the lowest energy geometries, based on the lamarckian genetic algorithm (LGA) algorithm, using the Forcite Code [21, 22.

The universal force field (UFF) was selected to perform the calculations. After obtaining the best conformation of the geometries, the structures were submitted to a new optimization at the DFT level using the DMOL3 Code [23, 24], where the generalized gradient approximation (GGA) considers all the electrons of the molecules.

Molecular electrostatic potential surfaces were investigated to identify the most reactive nucleophilic and electrophilic regions. We performed molecular docking with the ArgusLab 4.0.1 program. There are two options for docking algorithms, the first one is GA dock (Genetic Algorithm), and the other one is Argusdock (Shape-Based Search Algorithm). 
The calculations are from GAdock docking algorithms, which take into account the Lamarckian Genetic Algorithm. The docking location was defined using a box with coordinates $47.25 \times 36.00 \times 49.75 \AA$, spacing of $0.400 \AA$, and flexible binder coupling mode.

\section{Results and discussion}

\subsection{Optimization and electrostatic interaction}

Figures 1 A, B and C show the optimized structures and the numbering of the atoms forming the acids kaurenoic, copalic, and $\beta$-caryophyllene. The $\mathrm{H}$ bond represents an interaction between two electronegative atoms.

Table 1 illustrates their total energies (ET), binding energy (BE) and maximum cartesian force (MCF) of these acids. The global minimum energies are found to be -922.5966100 a.u $(-25105 \mathrm{eV}),-924.0927850$ a.u $(-25145 \mathrm{eV})$, $580.6642644(-15800 \mathrm{eV})$ for kaurenoic, copalic and $\beta$-caryophyllene, respectively.

Table 1: Calculated total energies (ET), binding energy (BE) and maximum cartesian force (MCF) of acids kaurenoic, copalic and $\beta$-caryophyllene.

\begin{tabular}{cccc}
\hline Molecules & ET $($ Hartree $)$ & BE $(\mathrm{Kcal} / \mathrm{mol})$ & $\mathrm{MCF}$ \\
\hline Kaurenoic & -922.5966100 & -10.56 & $0.139052 \times 10^{-2}$ \\
Copalic & -924.0927850 & -10.77 & $0.495639 \times 10^{-3}$ \\
$\beta$-caryophyllene & -580.6642644 & -10.96 & $0.196084 \times 10^{-2}$ \\
\hline
\end{tabular}

The binding energy of the protein spike with kaurenoic acid was -10.56 $\mathrm{kcal} / \mathrm{mol}$, with copalic it was $-10.77 \mathrm{kcal} / \mathrm{mol}$, and with $\beta$-caryophyllene, it was $-10.96 \mathrm{kcal} / \mathrm{mol}$. Negative values of binding energies suggest the stability of the complexes.

Their maximum Cartesian forces are found to be $0.139052 \times 10^{-2}, 0.495639 \times$ $10^{-3}$ and $0.196084 \times 10^{-2}$, as can be seen in table 1 . The addition of other atoms in the geometry of compounds influences their stability. We can notice in table 1 that the $\beta$-caryophyllene compound is the most stable because the globalminimum energy is the smallest compared to the other acids ones.

Fig. 2 shows the maps of molecular electrostatic potential (MEPs) of the copaiba oil-forming acid molecules. The MEP is a tool used to describe the most reactive nucleophilic and electrophilic regions of a molecule against reactive biological potentials and intermolecular interactions [25, 26]. The electrophilic site indicates strong attraction and the nucleophilic site indicates strong repulsion. In these regions, the formation of hydrogen bonds occurs. MEPs provide regions of negative, positive and neutral electrostatic potential in terms of color grading and are an indicator in researching molecular structure properties. Atoms in red represent the most electronegative electrostatic potential; atoms in this region tend to attract electrons (electrophilic). Atoms in blue indicates the most electropositive potential atoms in this region tend to repel electrons (nucleophilic). 


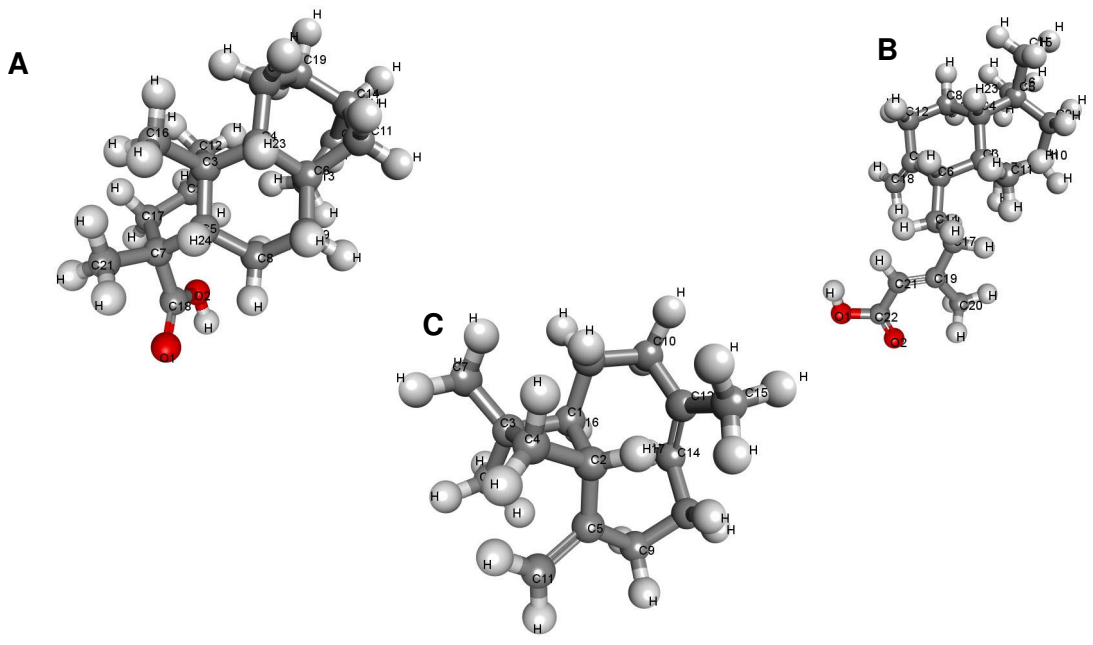

Figure 1: Optimization of acids kaurenoic in A, copalic in B and $\beta$-caryophyllene in $\mathrm{C}$.

In yellow we can see the forming acids of the copaiba oil (binders). As a result, the surfaces of the MEPs range from -0.100 a.u (deepest red) to $0.100 \mathrm{a} . \mathrm{u}$ (deepest blue) for the three compounds.

\subsection{Molecular docking and 2D visual representations}

Figures 3A, B, and C show the molecular docking of kaurenoic, copalic, and $\beta$-caryophyllene acids interacting with the spike protein of Sars-CoV-2. The purpose of docking is determine the modes of interaction of ligands (copaiba oil-forming acids) while organizing favorable orientations for the binding of a ligand to a receptor 27 31].

The receptor represents the COVID-19 protein that has one or more specific active sites. In this work, before coupling, all native ligands and water molecules were removed from the protein structure. In addition, polar hydrogen atoms are added and Kollman atom charges are assigned to protein atoms. At each step of the calculation, the interactions are affected, and the best orientation of ligands was determined to investigate the different types of interactions between the copaiba oil-forming compounds and the protein.

Figures 4 A, B, C, and table 2 illustrate the dockings of the copaiba oil compounds against the Sars-CoV-2 receptor binding site complexed with its receptor (PDB ID: 6M0J). The figs and table also show the interaction of kaurenoic acid with TRP:271, ARG:273, LEU:144, TYR:127, LEU:503, HIS:505, PHE:504, PHE274, MET:270, ASN:149 and ASP:269; Copalic acid with HIS:505, PHE:504, ARG:273, TYR:515, TYR:127, ASN:508, SER:128, TRP:271 and LEU:503, and $\beta$-caryophyllene acid with LEU:733 , LEU:391, PHE:390, PHE:32, TRP:69, PHE:40, ARG:393, ASN:271, LEU:100 and ALA:36 


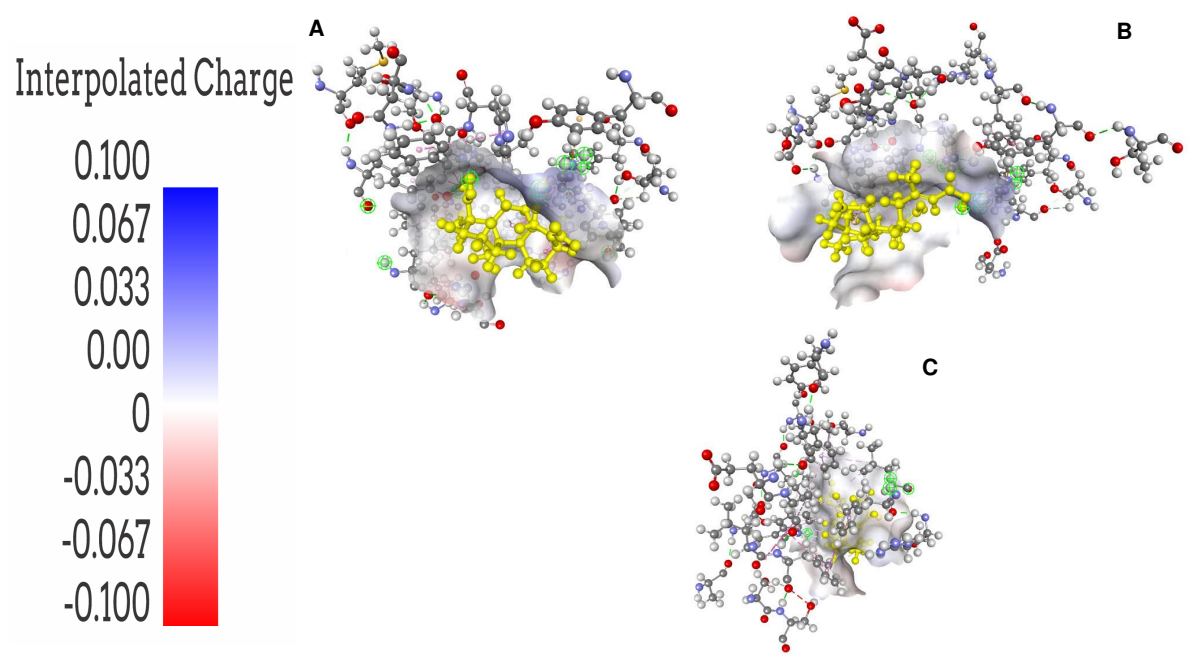

Figure 2: Different interactions between the kaurenoic acids in $\mathrm{A}$, copalic acids in $\mathrm{B}$ and $\beta$-caryophyllene in $\mathrm{C}$ and protein spike.
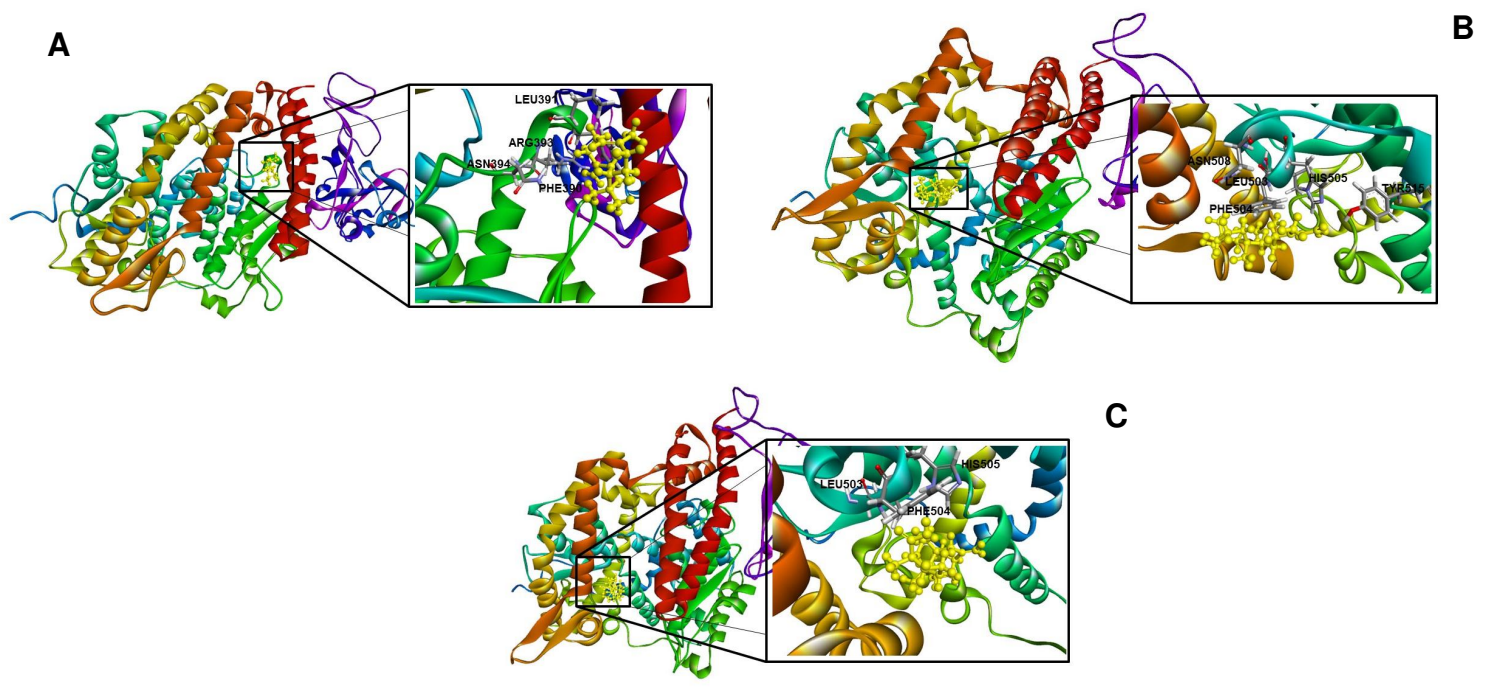

Figure 3: Amino acids were obtained from RBD. Orientation of acids kaurenoic in A, copalic in $\mathrm{B}$, and $\beta$-caryophyllene in $\mathrm{C}$ on the active sites of COVID-19 proteins. 


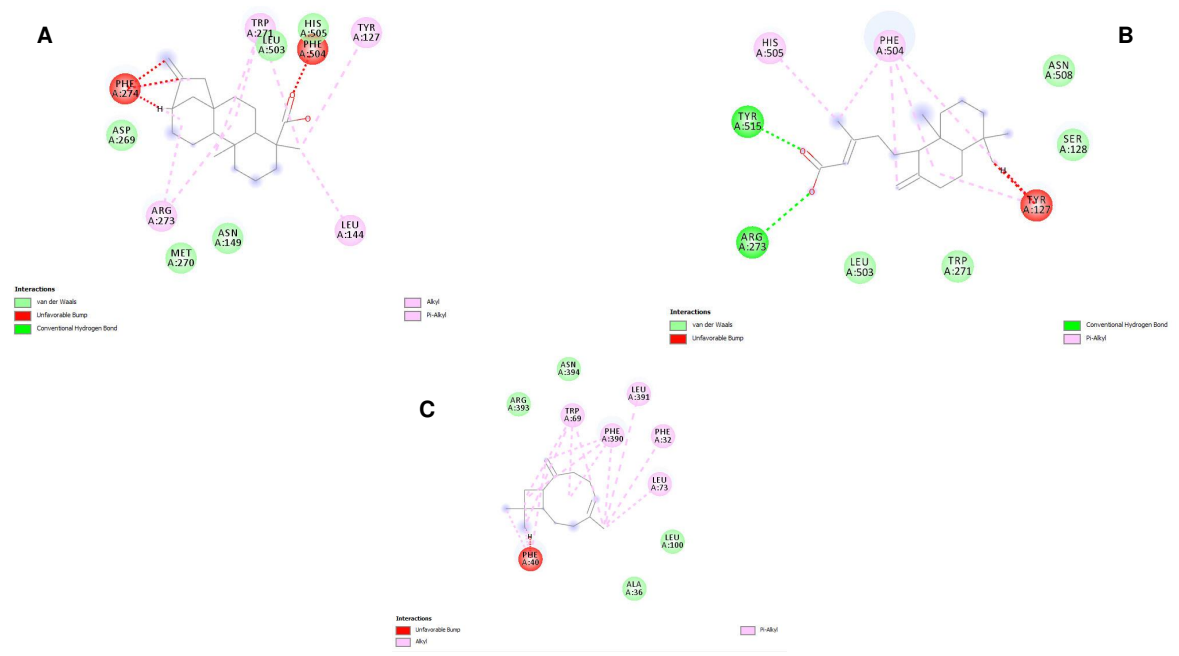

Figure 4: 2D visual representations of the acids kaurenoic in $\mathrm{A}$, copalic in $\mathrm{B}$ and $\beta$ caryophyllene in C.

Furthermore, in kaurenoic acid the alkyl interaction was observed surrounded by the amino acid TRP:271 having a distance of $1.54616 \AA$. Pi-Alkyl interactions are surrounded by amino acids ARG:273, LEU:144, and TYR:127 having distances of $1.53098 \AA, 1.52469 \AA$, and $1.44887 \AA$, respectively. Conventional H-bond interactions are surrounded by amino acids LEU:5034 and HIS:505 with $1.53046 \AA$ and $1.09958 \AA$, respectively.

Unfavorable bump interactions are surrounded by amino acids PHE:504 and PHE:274 with $1.40918 \AA$ and $1.55124 \AA$, respectively. Van der Waals interactions are surrounded by amino acids MET:270, ASN:149, and ASP:269 with of $1.80711 \AA, 1.54968 \AA$, and $1.52356 \AA$, respectively.

In copalic acid, alkyl interactions were observed surrounded by amino acids HIS:505 and PHE:504 with $1.51632 \AA$ and $1.53555 \AA$, respectively. Conventional H-bond interactions are surrounded by amino acids ARG:273 and TYR:515 with $1.53098 \AA$ and $1.36785 \AA$, respectively. Van der Waals interactions are surrounded by amino acids ASN:508, SER:128, and TRP:271 with $1.53108 \AA$, $1.52889 \AA$, and $1.54616 \AA$, respectively.

In the $\beta$-caryophyllene acid, the alkyl interaction is surrounded by the amino acid LEU:733 with $1.52373 \AA$. Pi-Alkyl interactions are surrounded by amino acids LEU:391, PHE:390, PHE:32, and TRP:69 with $1.52737 \AA, 1.53217 \AA$, $1.52478 \AA$, and $1.53147 \AA$, respectively. The Unfavorable bump interaction is surrounded by the amino acid PHE:40 with $1.09015 \AA$. Van der Waals interactions are surrounded by amino acids ARG:393, ASN:271, LEU:100, and ALA:36 with $1.52876 \AA, 1.51483 \AA, 1.52757$, and $1.52554 \AA$, respectively. 
Table 2: Amino acid residues of acids kaurenoic, copalic and $\beta$-caryophyllene. Target protein ID: $6 \mathrm{M} 0 \mathrm{~J}$.

\begin{tabular}{|c|c|c|c|c|}
\hline Ligand & Binding residue & Type & Bond length $(\AA)$ & Interactions \\
\hline \multirow[t]{11}{*}{ Kaurenoic } & TRP:271 & Tryptophan & 1.54616 & Alkyl \\
\hline & ARG:273 & Arginine & 1.53098 & Pi-Alkyl \\
\hline & LEU:144 & Leucine & 1.52469 & Pi-Alkyl \\
\hline & TYR:127 & Tyrosine & 1.44887 & Pi-Alkyl \\
\hline & LEU:503 & Leucine & 1.53046 & Conventional H-bond \\
\hline & HIS:505 & Histidine & 1.09958 & Conventional H-bond \\
\hline & PHE:504 & Phenylalanine & 1.40918 & Unfavorable bump \\
\hline & PHE:274 & Phenylalanine & 1.55124 & Unfavorable bump \\
\hline & MET:270 & Methionine & 1.80711 & Van der Waals \\
\hline & ASN:149 & Asparagine & 1.54968 & Van der Waals \\
\hline & ASP:269 & Aspartate & 1.52356 & Van der Waals \\
\hline \multirow[t]{9}{*}{ Copalic } & HIS:505 & Histidine & 1.51632 & Alkyl \\
\hline & PHE:504 & Phenylalanine & 1.53555 & Alkyl \\
\hline & ARG:273 & Arginine & 1.53098 & Conventional H-bond \\
\hline & TYR:515 & Tyrosine & 1.36785 & Conventional H-bond \\
\hline & TYR:127 & Tyrosine & 1.36785 & Unfavorable bump \\
\hline & ASN:508 & Asparagine & 1.53108 & Van der Waals \\
\hline & SER:128 & Serine & 1.52889 & Van der Waals \\
\hline & TRP:271 & Tryptophan & 1.54616 & Van der Waals \\
\hline & LEU:503 & Tryptophan & 1.54616 & Van der Waals \\
\hline \multirow[t]{12}{*}{$\beta$ caryophyllene } & $\begin{array}{c}\text { LEU:733 } \\
\text { Alkyl }\end{array}$ & Leucine & 1.52373 & \\
\hline & LEU:391 & Leucine & 1.52737 & \\
\hline & Pi-Alkyl & & & \\
\hline & PHE:390 & Phenylalanine & 1.53217 & Pi-Alkyl \\
\hline & PHE:32 & Phenylalanine & 1.52478 & Pi-Alkyl \\
\hline & TRP:69 & Tryptophan & 1.53147 & \\
\hline & Pi-Alkyl & & & \\
\hline & PHE:40 & Phenylalanine & 1.09015 & Unfavorable bump \\
\hline & ARG:393 & Arginine & 1.52876 & Van der Waals \\
\hline & ASN:271 & Asparagine & 1.51483 & Van der Waals \\
\hline & LEU:100 & Leucine & 1.52757 & Van der Waals \\
\hline & ALA:36 & Alanine & 1.52554 & Van der Waals \\
\hline
\end{tabular}




\section{Conclusion}

Considering the anti-inflammatory properties of copaiba oil, we studied three compounds that form the oil. We performed the classical optimizations calculations to obtain the most stable geometric conformation, using the conjugate gradient (LGA) and quantum gradient (GGA). The total and binding energies obtained for the three compounds were negative, which shows that the investigated complexes are stable. The $\beta$-caryophyllene is the most stable of the compounds, as its total energy was the lowest.

The calculated MEPs showed that regions with positive potentials are favorable to nucleophilic attack, while those regions with negative potentials are favorable to electrophilic attack. The results of molecular docking were discussed based on different interactions between acids (ligands) and proteins (receptors).

From the results obtained, it can be inferred that the acids that form the copaiba oil can be used as an inhibitor of COVID-19. These results encourage further in vitro and in vivo investigations into the pharmacological properties of copaiba oil.

\section{Acknowledgements}

The financial support for this research by CAPES (Coordenacão de Aperfeicoamento de Pessoal de Ensino Superior), is gratefully acknowledged W. O. Santos and J. R. da C. Venâncio were supported by a studentship from CAPES. LSCMN-PB (Laboratório de Simulação Computacional e Modelagem de Nanomateriais), LCC-PA (Laboratório de Computação Científica) of Federal University of the South and Southeast of Pará, CENAPAD-SP (Centro Nacional de Processamento de Alto Desempenho), LFA-PA (Laboratório de Física Aplicada) of Federal University of the South and Southeast of Pará and LFM-SE (Laboratório de Física Médica) of Federal University of Sergipe.

\section{Declarations}

Funding The research developed in this article had no financial support. Conflict of interest/ Competing interests Authors declare any not has financial and personal relationships with other people or organizations that could inappropriately influence in this work.

Availability of data and material The article files will be available upon request.

Code availability Not applicable.

Ethical approval Not applicable. The ethical standards have been met.

Authors' contributions Data collection, and analysis were performed by WO Santos, ALF Novais and ERP Novais. The first draft of the manuscript was written by WO Santos, ALF Novais, GC A Oliveira, JRC Venâcio and AM Rodrigues and all authors commented on previous versions of the manuscript. All authors contributed to the study conception and design and approved the final manuscript. 
Consent to participate Authors consent to participate in the research project, and they assure this research may not bring commercial benefit to us. Our participation is completely voluntary.

Consent for publication The authors declare that they agree with the submission and eventual publication..

\section{References}

[1] C. Hudson, F. Beaudette, Infection of the cloaca with the virus of infectious bronchitis, Science 76 (34) (1932) 34.

URL https://science.sciencemag.org/content/76/1958/34.2

[2] S. R. Weiss, S. Navas-Martin, Coronavirus pathogenesis and the emerging pathogen severe acute respiratory syndrome coronavirus, Microbiology and Molecular Biology Reviews 69 (4) (2005) 635-664. arXiv:https: //journals.asm.org/doi/pdf/10.1128/MMBR.69.4.635-664.2005 doi:10.1128/MMBR.69.4.635-664.2005.

URL https://journals.asm.org/doi/abs/10.1128/MMBR.69.4. 635-664.2005

[3] O. Noureddine, N. Issaoui, O. Al-Dossary, Dft and molecular docking study of chloroquine derivatives as antiviral to coronavirus covid19, Journal of King Saud University - Science 33 (1) (2021) 101248. doi:https://doi.org/10.1016/j.jksus.2020.101248. URL https://www.sciencedirect.com/science/article/pii/ S1018364720303621

[4] S. Belouzard, J. K. Millet, B. N. Licitra, G. R. Whittaker, Mechanisms of coronavirus cell entry mediated by the viral spike protein, Viruses 4 (6) (2012) 1011-1033. doi:10.3390/v4061011. URL https://www.mdpi.com/1999-4915/4/6/1011

[5] V. S. Shaikh, Y. I. Shaikh, K. Ahmed, A. An, S. Sagar, A molecular docking study of lopinavir towards sars-cov-2 target protein Engineered Science 12 (2020) 113-116. doi:10.30919/es8d1226. URL http://dx.doi.org/10.30919/es8d1226

[6] F. Li, Structure, function, and evolution of coronavirus spike proteins, Annual Review of Virology 3 (1) (2016) 237-261. doi:10.1146/ annurev-virology-110615-042301.

URL https://doi.org/10.1146/annurev-virology-110615-042301

[7] H. Matter, C. Sotriffer, Applications and Success Stories in Virtual Screening John Wiley and Sons, Ltd, 2011, Ch. 12, pp. 319-358. arXiv:https: //onlinelibrary.wiley.com/doi/pdf/10.1002/9783527633326.ch12, doi:https://doi.org/10.1002/9783527633326.ch12.

URL https://onlinelibrary.wiley.com/doi/abs/10.1002/ 9783527633326.ch12 
[8] G. Wang, W. Zhu, Molecular docking for drug discovery and development: a widely used approach but far from perfect, Future Medicinal Chemistry 8 (14) (2016) 1707-1710, pMID: 27578269. arXiv:https://doi.org/10. 4155/fmc-2016-0143, doi:10.4155/fmc-2016-0143

URL https://doi.org/10.4155/fmc-2016-0143

[9] X.-Y. Meng, H.-X. Zhang, M. Mezei, M. Cui, Molecular docking: a powerful approach for structure-based drug discovery, Curr Comput Aided Drug 7 (2) (2011) 146-57. doi:10.2174/157340911795677602.

URL https://pubmed.ncbi.nlm.nih.gov/21534921/

[10] V. Salmaso, S. Moro, Bridging molecular docking to molecular dynamics in exploring ligand-protein recognition process: An overview, Frontiers in Pharmacology 9 (2018) 923. doi:10.3389/fphar.2018.00923.

URL https://www.frontiersin.org/article/10.3389/fphar.2018. 00923

[11] Q. S. Martins, C. A. Aguirre, J. Farias, Approach by raman and infrared spectroscopy in three vegetable oils from the brazilian amazon, Revista Mexicana de Física 65 (4) (2019) 328-332. doi:10.31349/RevMexFis.65. 328.

URL https://doi.org/10.31349/RevMexFis .65.328

[12] F. B. Teixeira, R. de Brito Silva, O. A. Lameira, L. P. Webber, R. S. D. Couto, M. D. Martins, R. R. Lima, Copaiba oil-resin (copaifera reticulata ducke) modulates the inflammation in a model of injury to rats' tongues, BMC Complementary Medicine and Therapies 17 (313). doi:10.1186/ s12906-017-1820-2.

URL https://doi.org/10.1186/s12906-017-1820-2

[13] M. Giorgetti, G. Negri, E. Rodrigues, Brazilian plants with possible action on the central nervous system - a study of historical sources from the 16th to 19th century, Journal of Ethnopharmacology 109 (2) (2007) 338-347. doi:https://doi.org/10.1016/j.jep.2006.08.003.

URL https://www.sciencedirect.com/science/article/pii/ S0378874106003862

[14] V. Veiga, E. Rosas, M. Carvalho, M. Henriques, A. C. Pinto, Chemical composition and anti-inflammatory activity of copaiba oils from copaifera cearensis huber ex ducke, copaifera reticulata ducke and copaifera multijuga hayne - a comparative study, Journal of Ethnopharmacology 112 (2) (2007) 248-254. doi:https://doi.org/10.1016/j.jep.2007.03.005 URL https://www.sciencedirect.com/science/article/pii/ S0378874107001286

[15] C. Herrero-Jáuregui, M. A. Casado, M. d. G. Bichara Zoghbi, R. C. Martins-da Silva, Chemical variability of copaifera reticulata ducke oleoresin, Chemistry \& Biodiversity 8 (4) (2011) 674-685. arXiv:https: 
//onlinelibrary.wiley.com/doi/pdf/10.1002/cbdv.201000258

doi:https://doi.org/10.1002/cbdv.201000258

URL https://onlinelibrary.wiley.com/doi/abs/10.1002/cbdv. 201000258

[16] J. M. Senedese, F. Rinaldi-Neto, R. A. Furtado, H. D. Nicollela, L. D. R. de Souza, A. B. Ribeiro, L. S. Ferreira, G. M. Magalhães, I. Z. Carlos, J. J. M. da Silva, D. C. Tavares, J. Kenupp Bastos, Chemopreventive role of copaifera reticulata ducke oleoresin in colon carcinogenesis, Biomedicine \& Pharmacotherapy 111 (2019) 331-337. doi:https://doi.org/10.1016/j.biopha.2018.12.091

URL https://www.sciencedirect.com/science/article/pii/ S0753332218379782

[17] F. C. de Souza, L. F. Brito, M. T. Silva, M. A. Sugimoto, A. C. S. Pinto, P. D. O. de Almeida, R. O. S. Souza, R. A. Costa, F. GuilhonSimplicio, A. G. Wanderley, K. M. T. de Oliveira, L. P. Sousa, V. F. da Veiga-Junior, E. S. Lima, Synthesis, characterization and in vitro, in vivo and in silico anti-inflammatory studies of the novel hybrid based on ibuprofen and 3-hydroxy-copalic acid isolated from copaiba oil (copaifera multijuga), J. Braz. Chem. Soc. 31 (7) (2020) 1335-1344. doi: 10.21577/0103-5053.20190266.

[18] C. V. Castro Ghizoni, A. P. Arssufi Ames, O. A. Lameira, C. A. Bersani Amado, A. B. Sá Nakanishi, L. Bracht, M. R. Marçal Natali, R. M. Peralta, A. Bracht, J. F. Comar, Anti-inflammatory and antioxidant actions of copaiba oil are related to liver cell modifications in arthritic rats, Journal of Cellular Biochemistry 118 (10) (2017) 3409-3423. arXiv:https://onlinelibrary.wiley.com/doi/pdf/ 10.1002/jcb.25998, doi:https://doi.org/10.1002/jcb.25998.

URL https://onlinelibrary.wiley.com/doi/abs/10.1002/jcb.25998

[19] L. M. Leandro, F. De Sousa Vargas, P. C. S. Barbosa, J. K. O. Neves, J. A. Da Silva, V. F. Da Veiga-Junior, Chemistry and biological activities of terpenoids from copaiba (copaifera spp.) oleoresins, Molecules 17 (4) (2012) 3866-3889. doi:10.3390/molecules17043866. URL https : //www .mdpi .com/1420-3049/17/4/3866

[20] R. A. Furtado, P. F. de Oliveira, J. M. Senedese, S. D. Ozelin, L. D. R. de Souza, L. F. Leandro, W. L. de Oliveira, J. J. M. da Silva, L. C. Oliveira, H. Rogez, S. R. Ambrósio, R. C. S. Veneziani, J. K. Bastos, D. C. Tavares, Assessment of genotoxic activity of oleoresins and leaves extracts of six copaifera species for prediction of potential human risks, Journal of Ethnopharmacology 221 (2018) 119-125. doi:https://doi.org/10.1016/j.jep.2018.04.002. URL https://www.sciencedirect.com/science/article/pii/ S0378874117335638 
[21] O. Ermer, Calculation of molecular properties using force fields. applications in organic chemistry, in: Bonding forces, Springer, 1976, pp. 161-211.

[22] A. Hagler, S. Lifson, P. Dauber, Consistent force field studies of intermolecular forces in hydrogen-bonded crystals. 2. a benchmark for the objective comparison of alternative force fields, Journal of the American Chemical Society 101 (18) (1979) 5122-5130.

[23] B. Delley, An all-electron numerical method for solving the local density functional for polyatomic molecules, The Journal of Chemical Physics 92 (1) (1990) 508-517. arXiv:https://doi.org/10.1063/1.458452, doi: $10.1063 / 1.458452$.

URL https://doi.org/10.1063/1.458452

[24] B. Delley, From molecules to solids with the $\mathrm{dmol}^{3}$ approach, The Journal of Chemical Physics 113 (18) (2000) 7756-7764. arXiv:https://doi.org/ 10.1063/1.1316015, doi:10.1063/1.1316015

URL https://doi.org/10.1063/1.1316015

[25] A. E. Reed, F. Weinhold, Natural localized molecular orbitals, The Journal of Chemical Physics 83 (4) (1985) 1736-1740. arXiv:https://doi.org/ 10.1063/1.449360, doi:10.1063/1.449360

URL https://doi.org/10.1063/1.449360

[26] H. Gokce, S. Bahceli, O. Akyildirim, H. Yuksek, O. G. Kol, The syntheses, molecular structures, spectroscopic properties (ir, micro- raman, $\mathrm{nmr}$ and $\mathrm{uv}$-vis) and dft calculations of antioxidant 3alkyl-4-[3-methoxy-4-(4-methylbenzoxy)benzylidenamino]-4,5-dihydro1h-1,2,4-triazol-5-one molecules, Letters in Organic Chemistry 10 (6). arXiv:https://doi.org/10.2174/15701786113109990001, doi:10.2174/15701786113109990001.

URL https://doi.org/10.1063/1.449360

[27] D. Duhovny, R. Nussinov, H. J. Wolfson, Efficient unbound docking of rigid molecules, in: R. Guigó, D. Gusfield (Eds.), Algorithms in Bioinformatics, Springer Berlin Heidelberg, Berlin, Heidelberg, 2002, pp. 185-200. doi: 10.1007/3-540-45784-4_14.

[28] D. Seeliger, B. de Groot, Tligand docking and binding site analysis with pymol and autodock/vina, Journal of Computer-Aided Molecular Design 24 (6) (2010) 417-422. doi:10.1007/s10822-010-9352-6.

URL https://doi .org/10.1007/s10822-010-9352-6

[29] K. Amin, M. Kamel, M. Anwar, M. Khedr, Y. Syam, Synthesis, biological evaluation and molecular docking of novel series of spiro $[(2 \mathrm{~h}, 3 \mathrm{~h})$ quinazoline-2,1- cyclohexan $]-4(1 \mathrm{~h})-$ one derivatives as anti-inflammatory and analgesic agents, European Journal of Medicinal Chemistry 45 (6) (2010) 2117-2131. doi:https: //doi.org/10.1016/j.ejmech.2009.12.078. 
URL https://www.sciencedirect.com/science/article/pii/ S0223523410000504

[30] L. Ahmed, B. Rasulev, M. Turabekova, D. Leszczynska, J. Leszczynski, Receptor- and ligand-based study of fullerene analogues: comprehensive computational approach including quantum-chemical, qsar and molecular docking simulations, Org. Biomol. Chem. 11 (2013) 5798-5808. doi:10. 1039/C30B40878G.

URL http://dx.doi.org/10.1039/C30B40878G

[31] H. Ghalla, N. Issaoui, F. Bardak, A. Atac, Intermolecular interactions and molecular docking investigations on 4-methoxybenzaldehyde, Computational Materials Science 149 (2018) 291-300. doi:https: //doi.org/10.1016/j.commatsci.2018.03.042.

URL https://www.sciencedirect.com/science/article/pii/ S0927025618301952 